\title{
Editorial
}

\section{Periprosthetic Infection}

\author{
Enrique Guerado ${ }^{*}$,
}

Department of Orthopaedic Surgery and Traumatology, Hospital Costa del Sol, Autovía A-7 Km, 187, 29603, Marbella (Malaga), Spain

Periprosthetic infection is a common and challenging problem in current orthopaedic surgery practice. It can result in a devastating clinical outcome and be very costly to treat. In some cases, infection is lifelong.

Any implant for arthroplasty or osteosynthesis may be subject to infection [1]. However, the frequency and nature of such infection remain to be accurately characterised. Proposed definitions take into account only the objective criteria obtained from direct clinical observation or by diagnostic tools [2]. Nevertheless, it is well known that months or even years after the apparent disappearance of infection, a new episode of local clinical sepsis can develop spontaneously.

Prevention, on the one hand, and careful epidemiological surveillance on the other, of infections in the orthopaedic department can maintain the incidence of infection within a "tolerable" range. Despite this, diagnosis remains most solidly grounded by a retrospective review of clinical history, when the infection has already become apparent [3]. Microbiological tests to confirm the existence of infection can fail due to false positive contamination, false negative (difficult to culture) microorganisms or antibiotic treatment. New developments in the diagnosis of infection are continually being presented, but none has yet proven infallible [4-6].

Even retrospective epidemiological short or mediumterm follow up can fail to detect whether a patient will suffer in the future from periprosthetic infection, because this may develop at any time after the primary operation, either as a result of silent infection or due to newly-developed bacteraemia.

\footnotetext{
*Address correspondence to this author at the Department of Orthopaedic Surgery and Traumatology, Hospital Costa del Sol, Autovía A-7 Km, 187, 29603, Marbella (Malaga), Spain; Tel: 349519766 69;

E-mail: eguerado@hcs.es

${ }^{\S}$ Guest Editor
}

The majority of these patients need more than one surgical debridement. An aggressive approach, meticulously removing necrotic or ischaemic infected soft tissue, together with peri-implant vascularisation enhancement, is the most effective basis for pharmacological treatment. Antibiotic administration consists of a single or, more frequently, a combination of antibiotics determined in accordance with the findings of a positive culture. It is currently accepted that treatment must be conducted by an orthopaedic surgeon in collaboration with a physician specialised in infectious diseases and in antibiotic management [1]. Nevertheless, early or late antibiotic resistance may require treatment changes. If the infection continues, implant removal may be necessary, followed, in due course, by the insertion of a new implant. Nevertheless, the soundness of this procedure, known as two-stage revision, has yet to be fully established.

The advantages and problems of medical and surgical techniques for the diagnosis and treatment of periprosthetic infection are analysed in this issue of the Open Orthopaedic Journal.

\section{REFERENCES}

[1] Cobo J, Del Pozo JL. Prosthetic joint infection: diagnosis and management. Expert Rev Anti Infect Ther 2011; 9(9): 787-802.

[2] Parvizi J, Zmistowski B, Berbar EF, et al. New definition for periprosthetic joint infection: from the workgroup of the Musculoskeletal Infection Society. Clin Orthop Relat Res 2011; 469: 2992-4.

[3] Epine. http: //hws.vhebron.net/epine/Descargas/EPINE\%202011\% 20ESPA\%C3\%91A\%20Resumen.pdf [Last Accessed: December 2012].

[4] Trampuz A, Piper KE, Jacobson MJ, et al. Sonication of removed hip and knee prostheses for diagnosis of infection. N Engl J Med 2007; 357 (7): 654-63.

[5] Marín M, Garcia-Lechuz JM, Alonso P, et al. Role of universal $16 \mathrm{~S}$ rRNA gene PCR and sequencing in diagnosis of prosthetic joint infection. J Clin Microbiol 2012; 50(3): 583-9.

[6] Kwee TC, Kwee RM, Alavi A. FDG-PET for diagnosing prosthetic joint infection: systematic review and metaanalysis. Eur J Nucl Med Mol Imaging 2008; 35: 2122-32.

(C) Enrique Guerado; Licensee Bentham Open.

This is an open access article licensed under the terms of the Creative Commons Attribution Non-Commercial License (http://creativecommons.org/licenses/by-nc/3.0/) which permits unrestricted, non-commercial use, distribution and reproduction in any medium, provided the work is properly cited. 